\title{
Autoimmune hepatitis diagnosed by endoscopic ultrasound-guided liver biopsy using a new 19-gauge histology needle
}

An 85-year-old woman presented with elevated liver function tests. A computed tomography (CT) scan showed normal liver morphology and a cyst in the pancreas. Viral hepatitis serology was negative but tests for autoimmune disease were positive: antinuclear antibody $1: 320$, antismooth muscle antibody $1: 40$, immunoglobulin G level $2600 \mathrm{mg} / \mathrm{dL}$. The patient underwent endoscopic ultrasound (EUS)guided fine needle aspiration of the pancreatic cyst, which showed mucinous fluid with CEA $3939 \mathrm{ng} / \mathrm{mL}$, consistent with a mucinous cyst. She then underwent EUS-guided fine needle biopsy (FNB) of the left lobe of liver using a new 19-gauge histology needle (EchoTip ProCore; Cook Medical Inc., Bloomington, Indiana, USA) via a transgastric approach. A single pass was made with multiple toand-fro movements and multiple specimens up to $15 \mathrm{~mm}$ were obtained ( Fig.1). Pathological examination revealed eight portal tracts and moderate portal infiltration and interface hepatitis, and along with serologic testing, confirmed the diagnosis of autoimmune hepatitis ( Fig.2) [1]. There were no procedure-related complications.

Despite the advancement of less invasive diagnostic tools [2], liver biopsy is still the gold standard for diagnosis of benign liver parenchymal disease. Recently, EUSguided liver biopsy using the Tru-cut needle has been reported $[3,4]$. One of the limitations of EUS-guided FNB is the needle size. In addition, the Tru-cut needle allows only a one-shot biopsy with a 20-mm-long tray. The new histology needle can potentially obtain longer specimens via multiple to-and-fro movements, analogous to a cheese grater, with the hollow of the needle. Fan-like movement of the needle can also increase the sampling area through one puncture site. Theoretically, the small needle and single puncture under EUS guidance may result in fewer bleeding complications. Patients who require endoscopy for other reasons may be candidates for EUS-guided liver biopsy. The feasibility of this 19-gauge histology needle [5] has been reported,

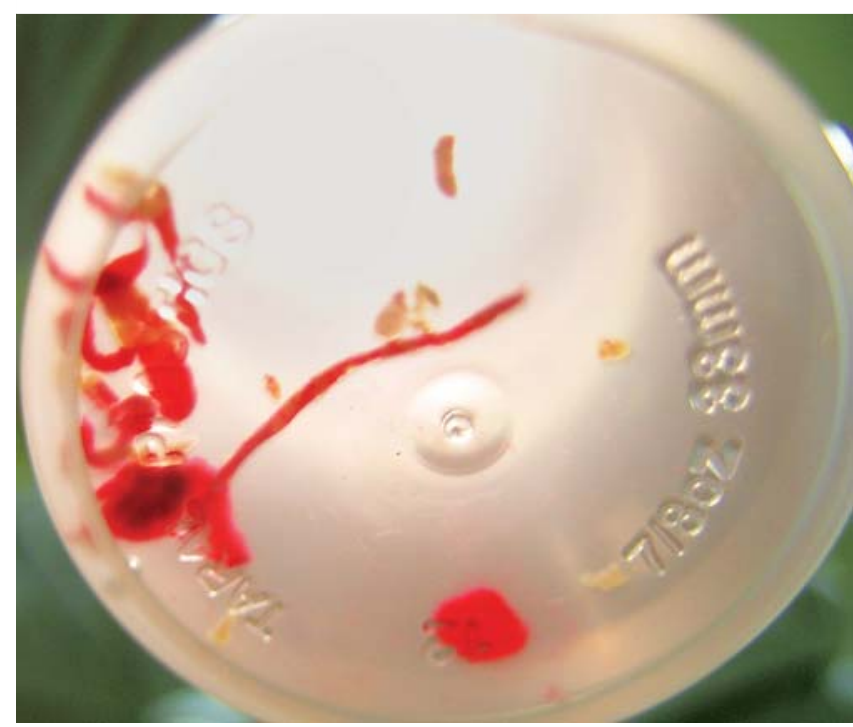

Fig. 1 Macroscopic view of EUS-guided liver biopsy core in an elderly woman with elevated liver function tests.

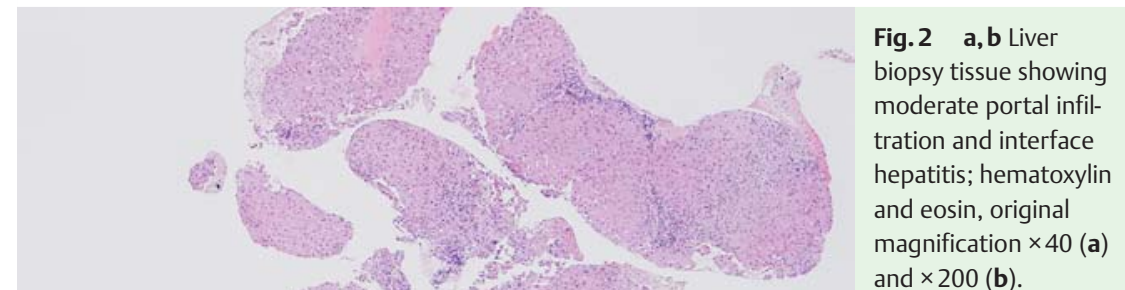

Fig. 2 a, b Liver biopsy tissue showing erate portal infihepatitis; hematoxylin magnification $\times 40(a)$ and $\times 200$ (b)

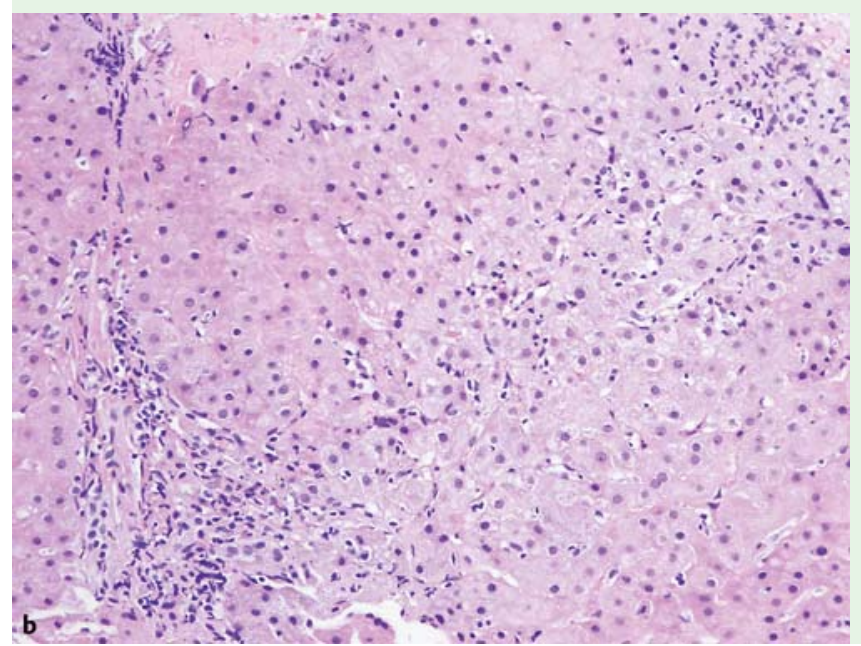


but a prospective study is needed to confirm the feasibility, safety, and yield of this histology needle for EUS-guided liver biopsy.

Endoscopy_UCTN_Code_TTT_1AS_2AF

Competing interests: None

\section{Y. Nakai, J. B. Samarasena,}

\section{T. Iwashita, D. H. Park, J. G. Lee,}

\section{K. Q. Hu, K. J. Chang}

H. H. Chao Comprehensive Digestive Center, University of California, Irvine Medical Center, Orange, California, USA

\section{References}

1 Hennes EM, Zeniya M, Czaja AJ et al. Simplified criteria for the diagnosis of autoimmune hepatitis. Hepatology 2008; 48: $169-176$

2 Masuzaki R, Tateishi R, Yoshida $H$ et al. Assessing liver tumor stiffness by transient elastography. Hepatol Int 2007; 1: 394-397

3 Gleeson FC, Clayton AC, Zhang L et al. Adequacy of endoscopic ultrasound core needle biopsy specimen of nonmalignant hepatic parenchymal disease. Clin Gastroenterol Hepatol 2008; 6: 1437-1440

4 Dewitt J, McGreevy K, Cummings $O$ et al. Initial experience with EUS-guided Tru-cut biopsy of benign liver disease. Gastrointest Endosc 2009; 69: 535-542

5 Iglesias-Garcia J, Poley JW, Larghi A et al. Feasibility and yield of a new EUS histology needle: results from a multicenter, pooled, cohort study. Gastrointest Endosc 2011; 73: 1189-1196

\section{Bibliography}

DoI http://dx.doi.org/ 10.1055/s-0031-1291567 Endoscopy 2012; 44: E67-E68 (c) Georg Thieme Verlag KG Stuttgart · New York ISSN 0013-726X

\section{Corresponding author}

\section{K. J. Chang}

101 The City Drive Building $23 \mathrm{C}$

Orange

California 92868

USA

Fax: +1-714-456-5820

kchang@uci.edu 